\title{
NEMO-ICB (v1.0): interactive icebergs in the NEMO ocean model globally configured at eddy-permitting resolution
}

\author{
R. Marsh ${ }^{1}$, V. O. Ivchenko ${ }^{1}$, N. Skliris ${ }^{1}$, S. Alderson ${ }^{2}$, G. R. Bigg ${ }^{3}$, G. Madec $^{2,4}$, A. T. Blaker ${ }^{2}$, Y. Aksenov ${ }^{2}$, B. Sinha ${ }^{2}$, \\ A. C. Coward ${ }^{2}$, J. Le Sommer ${ }^{5}$, N. Merino ${ }^{5}$, and V. B. Zalesny ${ }^{6}$ \\ ${ }^{1}$ University of Southampton, National Oceanography Centre, Southampton, UK \\ ${ }^{2}$ National Oceanography Centre, Southampton, European Way, Southampton SO14 3ZH, UK \\ ${ }^{3}$ Department of Geography, University of Sheffield, Sheffield, UK \\ ${ }^{4}$ LOCEAN-IPSL, CNRS-IRD-UPMC-MNHN, Paris, France \\ ${ }^{5}$ LGGE, UMR5183, CNRS-UJF, Grenoble, France \\ ${ }^{6}$ Institute of Numerical Mathematics, Russian Academy of Sciences, Gubkin St. 8, Moscow, 119333, Russia
}

Correspondence to: R. Marsh (rm12@soton.ac.uk)

Received: 23 June 2014 - Published in Geosci. Model Dev. Discuss.: 25 August 2014

Revised: 27 February 2015 - Accepted: 13 April 2015 - Published: 27 May 2015

\begin{abstract}
An established iceberg module, ICB, is used interactively with the Nucleus for European Modelling of the Ocean (NEMO) ocean model in a new implementation, NEMO-ICB (v1.0). A 30-year hindcast (1976-2005) simulation with an eddy-permitting $\left(0.25^{\circ}\right)$ global configuration of NEMO-ICB is undertaken to evaluate the influence of icebergs on sea ice, hydrography, mixed layer depths (MLDs), and ocean currents, through comparison with a control simulation in which the equivalent iceberg mass flux is applied as coastal runoff, a common forcing in ocean models. In the Southern Hemisphere ( $\mathrm{SH}$ ), drift and melting of icebergs are in balance after around 5 years, whereas the equilibration timescale for the Northern Hemisphere (NH) is 15-20 years. Iceberg drift patterns, and Southern Ocean iceberg mass, compare favourably with available observations. Freshwater forcing due to iceberg melting is most pronounced very locally, in the coastal zone around much of Antarctica, where it often exceeds in magnitude and opposes the negative freshwater fluxes associated with sea ice freezing. However, at most locations in the polar Southern Ocean, the annual-mean freshwater flux due to icebergs, if present, is typically an order of magnitude smaller than the contribution of sea ice melting and precipitation. A notable exception is the southwest Atlantic sector of the Southern Ocean, where iceberg melting reaches around $50 \%$ of net precipitation over a large area. Including icebergs in place of coastal runoff, sea ice concentration and thickness are notably decreased at most
\end{abstract}

locations around Antarctica, by up to $\sim 20 \%$ in the eastern Weddell Sea, with more limited increases, of up to $\sim 10 \%$ in the Bellingshausen Sea. Antarctic sea ice mass decreases by $2.9 \%$, overall. As a consequence of changes in net freshwater forcing and sea ice, salinity and temperature distributions are also substantially altered. Surface salinity increases by $\sim 0.1 \mathrm{psu}$ around much of Antarctica, due to suppressed coastal runoff, with extensive freshening at depth, extending to the greatest depths in the polar Southern Ocean where discernible effects on both salinity and temperature reach $2500 \mathrm{~m}$ in the Weddell Sea by the last pentad of the simulation. Substantial physical and dynamical responses to icebergs, throughout the global ocean, are explained by rapid propagation of density anomalies from high-to-low latitudes. Complementary to the baseline model used here, three prototype modifications to NEMO-ICB are also introduced and discussed.

\section{Introduction}

Freshwater fluxes from the terrestrial cryosphere comprise liquid runoff and calved icebergs. This partitioning is believed to be significant for freshwater distribution in the oceans (Gladstone et al., 2001). Runoff freshens the ocean locally near the coast, while individual icebergs represent pathways for continuous and increasingly remote freshwater 
influence on the open ocean (Bigg and Wadley, 1996; Bigg et al., 1997).

In order to accommodate the climatic influence of icebergs, principally through the freshwater input to the ocean, it is necessary to model their statistical distribution, rather than track large numbers of individual bergs (Hunke and Comeau, 2011). Interactive ocean-iceberg modelling began with the development of an ocean-forced iceberg trajectory model (Bigg and Wadley, 1996). An iceberg momentum balance accounts for Coriolis and pressure gradient forces, plus drag forces from ocean, wind, waves, and sea ice. Along each trajectory, iceberg mass is reduced according to parameterizations of basal melting, buoyant convection, and wave erosion. This model has been extensively used and validated in the Arctic (e.g. Bigg and Wadley, 1996) and Antarctic (Gladstone et al., 2001), as well as for palaeoclimate studies (e.g. Watkins et al., 2007).

The iceberg model was subsequently coupled with the Fine-Resolution Greenland Sea and Labrador Sea (FRUGAL) ocean model, which features a curvilinear grid system with a North Pole centred in Greenland, ensuring reasonably high resolution $(20-50 \mathrm{~km})$ in the northern Atlantic and Arctic (Wadley and Bigg, 2000). This coupling allows for feedback between iceberg meltwater and the surface ocean dynamics and thermodynamics (Levine and Bigg, 2008). For a given calving flux, a distribution of icebergs is specified in terms of size, with characteristic length, width and thickness.

In separate developments, modified versions of the Bigg and Wadley (1996) and Bigg et al. (1997) iceberg model have been coupled with the ECBilt-CLIO Earth System Model (Jongma et al., 2009) and with CM2G, a next-generation GFDL (Geophysical Fluid Dynamics Laboratory) climate model, featuring an isopycnal-coordinate ocean component (Martin and Adcroft, 2010; henceforth MA10). Jongma et al. (2009) found that freshening and cooling influences of icebergs enhance sea ice area by 12 and $6 \%$, respectively. MA10 conversely found that sea ice cover is generally thinner and less compact with icebergs, compared to a control experiment in which fresh water enters the ocean at the coast and stimulates sea ice growth. They found the strongest decreases in sea ice concentration of 6-8\% in the Amundsen, Bellingshausen, Weddell, and D'Urville seas, i.e. along the major export routes for icebergs. The reduced freshwater input over continental shelf regions in experiments with icebergs (in particular, the flux of "bergy bits") enhances deepwater formation in $\mathrm{CM} 2 \mathrm{G}$, leading to an increase of up to $10 \%$ in the production rate of model Antarctic Bottom Water.

It should be noted that the iceberg mass fluxes and distributions in CM2G - and the aforementioned impacts - are associated with calving rates, in balance with precipitation over ice sheets, that are rather different from observations. We also note that Jongma et al. (2009) distributed Antarctic runoff globally in the control experiment, in contrast to the control run with $\mathrm{CM} 2 \mathrm{G}$, which could explain the opposing sea ice trends associated with the introduction of icebergs to ECBilt-CLIO and CM2G.

In the present study, a modified version of the Bigg and Wadley (1996) and Bigg et al. (1997) iceberg model, developed by MA10, is coupled to an eddy-permitting global implementation of the Nucleus for European Modelling of the Ocean (NEMO) (Madec, 2008), to simulate the trajectories and melting of calved icebergs - from Antarctica, Greenland, and small northern ice caps - in the presence of mesoscale variability and fine-scale dynamical structure. In contrast, both MA10 and Jongma et al. (2009) included icebergs in models with coarse (non-eddy resolving) ocean resolution.

The rest of the paper is organized as follows. In a model description section (Sect. 2), we provide details of the iceberg module (ICB), NEMO configuration, NEMO-ICB implementation, specified calving, experimental design, and diagnostics. In a model validation section (Sect. 3), we consider first the distribution of icebergs and the associated freshwater flux, followed by differences, attributed to the inclusion of icebergs, in sea ice, hydrography, mixed layer depths (MLDs) and ocean currents. In an additional section (Sect. 4), we describe prototype modifications of NEMOICB, in relation to the baseline configuration used here. In a summary and discussion section (Sect. 5), we compare and contrast our present results with observations and previous simulations, before highlighting some caveats related to physical processes that are yet to be included in coupled iceberg-ocean models. We conclude with details of code availability.

\section{Model description}

\subsection{The iceberg module}

The ICB (for ICeBergs) module is based on the original model of Bigg et al. (1997), as recently adapted for coupling to the CM2G climate model by MA10. Collections of icebergs are treated as Lagrangian particles, with the distribution of icebergs by size derived from observations. With increasing size (e.g. thickness ranging from 40 to $250 \mathrm{~m}$ ), smaller collections of icebergs are represented per particle - see Bigg et al. (1997) and MA10 for full details. The momentum balance for icebergs comprises the Coriolis force, air and water form drags, the horizontal pressure gradient force, a wave radiation force, and interaction with sea ice. The mass balance for an individual iceberg is governed by basal melting, buoyant convection at the sidewalls, and wave erosion (see Bigg et al., 1997). All respective equations are the same as detailed in MA10, so are not repeated here.

Internal stresses from the sea ice model are not directly used in the iceberg momentum balance, and similarly there is no feedback from the iceberg motion to the sea ice. Neglect of the momentum exchange between icebergs and sea ice is consistent with resolved length scales. The length scale 
of our biggest represented icebergs is $\sim 1 \mathrm{~km}$, and such icebergs are generally well dispersed around Antarctica, Greenland, and Arctic ice caps. Only near release sites will there be a sufficient iceberg density to perhaps impact sea ice motion, which is determined on model grid scales that are more than 10 times larger than our largest icebergs. Independent of iceberg concentration, the impact of sea ice drag on icebergs is observed to be minimal around $80-90 \%$ of the time (Lighey and Hellmer, 2001), so the momentum interaction term, and any resulting feedback, may be regarded as second order. Only when the pack is concentrated does this change, and then there is a switch to the berg being carried by the sea ice. This step change in iceberg dynamics is not yet parameterized. We also assume that icebergs are oriented at $45^{\circ}$ relative to the wind, with the wind to the left (right) in the Northern Hemisphere (NH) (Southern Hemisphere - SH), as outlined in Bigg et al. (1997). This may or may not be the case in reality. Thus, any stress provided from the sea ice model grid is likely to be only approximate. For these reasons, a simple drag law - as implicit here (Eq. A.2c in MA10) - is realistic for iceberg interaction with sea ice. For higherresolution ocean models, with grid-cell dimensions of just a few kilometres, it would be necessary to more explicitly account for momentum transfers between icebergs and sea ice, but the present resolution prohibits such representation.

Sea ice concentration and thickness can also be impacted by freshwater fluxes from melting. Given the scale issues mentioned above, but the spreading of meltwater widely across the surface, one can argue that the effect of meltwater on these sea ice parameters is likely to be much greater than the imprecisely represented and resolved dynamical effect.

\subsection{NEMO version and configuration}

Interactive icebergs are implemented in NEMO v3.5, in a model option known as NEMO-ICB. The source code and forcing files used in the configurations presented here are available to registered NEMO users (see "Code availability"). The NEMO ocean model component is coupled to either the Louvain-la-Neuve sea ice model (LIM2) with viscous-plastic rheology, formulated by Fichefet and Maqueda (1997), or the Los Alamos National Laboratory sea ice model version 4.1 (CICE v4.1; see Hunke and Lipscomb, 2010). After initial NEMO-ICB development with LIM2 (Marsh et al., 2014), the results presented here are obtained with NEMO coupled to CICE. While testing of the latest NEMO versions is ongoing, validation of v3.4 demonstrated substantial improvements in surface physics over v3.2 (Megann et al., 2014).

\subsection{NEMO-ICB implementation - baseline and prototype versions}

Implementation of the ICB module within the NEMO framework differs from implementation of icebergs in the sea ice module of CM2G (MA10). The NEMO-ICB implementation was motivated by anticipated model development. Icebergs in the real world - up to $250 \mathrm{~m}$ thick in the model are largely submerged into the ocean, and therefore influenced by vertical temperature gradients and current shears. For physically correct model representation of iceberg-ocean interaction, model icebergs should correspondingly be submerged in the model ocean - difficult to code within the CM2G scheme.

The results presented here are obtained for icebergs interacting with surface currents and surface temperatures henceforth denoted the baseline version (for the available code, see "Code availability"). Besides the baseline version of the code, a number of optional modifications have been implemented and are currently being tested. In particular, this includes an option for advection of icebergs with depthaveraged currents, extending the dynamics routines to 3-D settings with minor code changes. Other optional modifications to the baseline version of the code include iceberg interaction with shallow bathymetry and computation of melting rates with the 3-D temperature field. These modifications are further described and discussed in Sect. 4 but are not yet readily available in the code.

As icebergs melt, freshwater is added to the surface level of the ocean model with salinity $0 \mathrm{psu}$ - effectively a frozen fraction of the total runoff in NEMO, re-distributed - freshening the ocean surface layer. There is no associated heat flux in the experiment presented here, although the option exists in NEMO-ICB for meltwater with a nominal temperature of $-4{ }^{\circ} \mathrm{C}$ to mix with the ocean. The additional mass flux associated with iceberg melt also alters the free surface height in NEMO.

\subsection{Iceberg calving}

Climatological iceberg calving rates are distributed realistically around coastlines in high latitudes of the $\mathrm{NH}$ and $\mathrm{SH}$ (as shown in Fig. 2a of Levine and Bigg, 2008), and the implied calving events are constant through time. The initial length / width ratio for all newly calved icebergs is 1.5 , and size distributions are specified as in MA10.

The total calving rate specified for Antarctica is $1140 \mathrm{Gt} \mathrm{year}^{-1}$, compared to $1332 \mathrm{Gt} \mathrm{year}^{-1}$ in Gladstone et al. (2001) and $1375 \mathrm{Gt} \mathrm{year}^{-1}$ in Levine and Bigg (2008) from $1500 \mathrm{~km}^{3}$ year -1 in the latter study, taking a standard density for ice, at $0^{\circ} \mathrm{C}$, of $916.7 \mathrm{~kg} \mathrm{~m}^{-3}$. While giant icebergs are unrepresented here, their absence does not account for these differences. Our Antarctic calving rate comprises $51.6 \%$ of total freshwater flux into the Southern Ocean from Antarctica $\left(2210 \mathrm{Gt} \mathrm{year}^{-1}\right.$ ), prescribed as $100 \%$ runoff in the absence of icebergs.

The mean calving rate in the $\mathrm{NH}$ is considerably smaller at $188 \mathrm{Gt} \mathrm{year}^{-1}$, compared to $206 \mathrm{Gt} \mathrm{year}^{-1}$ (from $225 \mathrm{~km}^{3}$ year $^{-1}$ ) in Levine and Bigg (2008). The great majority of northern hemispheric calving is from the Greenland 
ice sheet, with minor contributions from Axel Heiberg Island, Ellesmere Island, Devon Island, Bylot Island, Baffin Island, Svalbard, Franz Josef Island, Novaya Zemlya, and Severnaya Zemlya. Around Greenland, the calving rate comprises around $50 \%$ of total freshwater flux into the North Atlantic from the ice sheet.

It is noteworthy that our calving rates are derived from a mass balance calculation of around 2000, before melt and discharge from ice sheets began to increase significantly. Rignot et al. (2011) report steadily increasing rates of ice sheet mass discharge (remote sensing of ice motion and thickness) over 1992-2009, $\sim 500$ to $\sim 630 \mathrm{Gt} \mathrm{year}^{-1}$ for Greenland, and $\sim 2140$ to $\sim 2300 \mathrm{Gt} \mathrm{year}^{-1}$ for Antarctica. The partitioning of this discharge between calving and melting (basal melting of outlet glaciers and ice shelves) is poorly known and undoubtedly changing rapidly, but it is likely that recent calving rates are substantially higher than those used to develop earlier climatological rates, and trending upwards. In summary, our calving rates are conservative in the context of these ongoing changes, akin to "pre-industrial" estimates. The oceanographic and sea ice impacts reported here are therefore also likely to be conservative.

\subsection{Experimental design}

In common with preceding NEMO development (e.g. Megann et al., 2014), we undertook 30-year hindcast experiments, here for the period 1976-2005, with the $0.25^{\circ}$ resolution (eddy-permitting) global configuration known as ORCA025. We henceforth refer to corresponding NEMO experiments (without icebergs) as CONTROL, and NEMOICB experiments (with icebergs) as ICEBERG. In CONTROL, liquid freshwater (runoff) fluxes are prescribed at coastal grid cells around Antarctica, Greenland, and the smaller icecaps. This reference run is designed to emphasize the importance of icebergs in transporting freshwater, and we stress here that most DRAKKAR (see Megann et al., 2014) simulations with ORCA025 now use "static" 2-D maps of freshwater flux due to icebergs - e.g. for the Southern Ocean, the map is derived from Silva et al. (2006), or freshwater from melting icebergs is homogeneously spread south of $60^{\circ} \mathrm{S}$.

In ICEBERG, runoff around ice sheets is re-partitioned between iceberg calving and reduced runoff at coastal grid cells (spatially distributed as in CONTROL), such that the global ocean receives exactly the same freshwater flux in CONTROL and ICEBERG. Seasonal cycles of runoff are preserved through small adjustments at selected locations, while iceberg calving is constant throughout the year. We cannot guarantee that global-mean salinity will remain the same in both experiments, due to partial dependence of evaporation on sea surface temperature (SST), and the salinity relaxation scheme of NEMO. However, these effects on global-mean salinity are found to be very small (see Sect. 3.3).

\subsection{Diagnostics}

For a given time interval, the locations and properties of individual iceberg particles (each representative of varying numbers of icebergs in a given size class) are saved in a set of files that may be post-processed to obtain selected distributions and tracks for individual icebergs.

Integral diagnostics are written to the tracer files of standard NEMO output. Table 1 lists the full suite of these diagnostics, along with corresponding variable names and units. Most iceberg diagnostics are 2-D fields on the NEMO ocean model mesh. Particularly useful instantaneous measures of the iceberg model include the virtual coverage by icebergs - virtual in the sense that total grid-cell area is the sum of open water and sea ice, consistent with the very small fractional area for icebergs in the size categories considered here. Other important diagnostics are the melt rate of icebergs, in total and partitioned into three components named in the tracer files as "buoyancy component of iceberg melt rate" (basal melting); "convective component ..." (sidewall melting); "erosion component ..." (wave erosion).

\section{Model evaluation}

We first consider the spin-up of NEMO-ICB in terms of total iceberg volume. We then illustrate typical near-equilibrium iceberg distributions, based on year 26-30 (hindcast years 2001-2005) averages. We subsequently examine sea ice concentration and thickness, hydrography, MLDs, and preliminary evidence for iceberg influences on the global ocean circulation.

\subsection{Iceberg distribution and freshwater flux}

Time series of the total mass of icebergs (Fig. 1) indicate that global mass is dominated by southern hemispheric mass over northern hemispheric mass, in a ratio of around $4: 1$. We also note more inter-annual variability in the $\mathrm{SH}$, perhaps expected given the larger long-term mean. Southern hemispheric mass has equilibrated as early as year 5, while northern hemispheric mass equilibrates more slowly, due to the prevalence of semi-enclosed basins in the $\mathrm{NH}$ compared to the $\mathrm{SH}$, where icebergs become trapped. It requires some time for the mean iceberg mass of the Arctic in particular, but also Baffin Bay, to reach equilibrium. This extends the mean lifetime of northern hemispheric icebergs and delays equilibration relative to the SH by $10-15$ years. Icebergs are more rapidly exported from the Antarctic Coastal Current $(\mathrm{ACoC})$ to the Southern Ocean, where they melt relatively quickly, hence the shorter mean lifetime and equilibration timescale for southern hemispheric icebergs. However, the model does not include giant icebergs, of which there will always be some resident in the Southern Ocean (Silva et al., 2006) and which will take much longer to melt. The real ratio 
Table 1. Iceberg diagnostics saved in the standard NEMO tracer files.

\begin{tabular}{lll}
\hline Diagnostic & Variable name & Units \\
\hline Calving mass input & calving & $\mathrm{kg} \mathrm{s}^{-1}$ \\
Calving heat flux & calving_heat & - \\
Melt rate of icebergs + bits & berg_floating_melt & $\mathrm{kg} \mathrm{m}^{-2} \mathrm{~s}^{-1}$ \\
Accumulated ice mass by class & berg_stored_ice & $\mathrm{kg}^{-2}$ \\
Melt rate of icebergs & berg_melt & $\mathrm{kg} \mathrm{m}^{-2} \mathrm{~s}^{-1}$ \\
Buoyancy component of iceberg melting & berg_buoy_melt & $\mathrm{kg} \mathrm{m}^{-2} \mathrm{~s}^{-1}$ \\
Erosion component of iceberg melting & berg_eros_melt & $\mathrm{kg} \mathrm{m}^{-2} \mathrm{~s}^{-1}$ \\
Convective component of iceberg melting & berg_conv_melt & $\mathrm{kg} \mathrm{m}^{-2} \mathrm{~s}^{-1}$ \\
Virtual coverage by icebergs & berg_virtual_area & $\mathrm{m}^{2}$ \\
Mass source of bergy bits & bits_src & $\mathrm{kg} \mathrm{m}^{-2} \mathrm{~s}^{-1}$ \\
Melt rate of bergy bits & bits_melt & $\mathrm{kg} \mathrm{m}^{-2} \mathrm{~s}^{-1}$ \\
Bergy bit density field & bits_mass & $\mathrm{kg} \mathrm{m}^{-2}$ \\
Iceberg density field & berg_mass & $\mathrm{kg} \mathrm{m}^{-2}$ \\
Calving into iceberg class & berg_real_calving & $\mathrm{kg} \mathrm{s}^{-1}$ \\
\hline
\end{tabular}

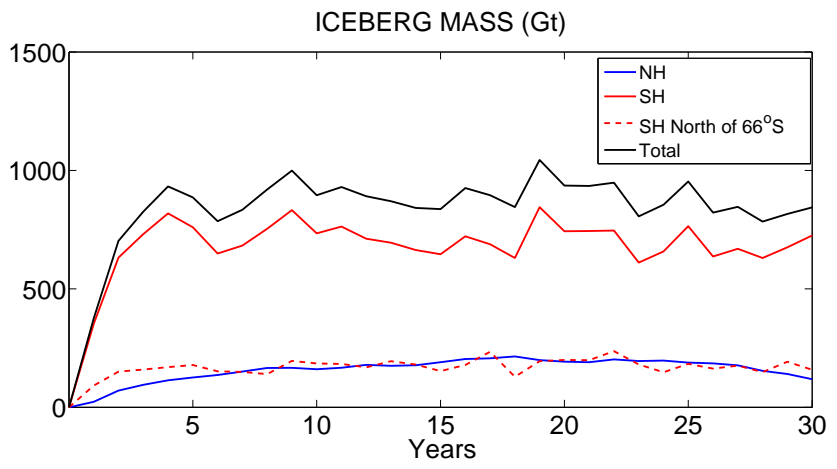

Figure 1. Time series of total iceberg mass $\left(1 \mathrm{Gt}=10^{9}\right.$ tonne $=10^{12} \mathrm{~kg}$ ); southern hemispheric and northern hemispheric iceberg mass is indicated by the red and blue lines, respectively. Southern hemispheric iceberg mass north of $66^{\circ} \mathrm{S}$ (dashed red line) is shown for comparison with observations of Tournadre et al. (2012).

of iceberg mass between the hemispheres is therefore likely to be greater than in the model.

The year 26-30 mean global iceberg mass of $800-1000 \mathrm{Gt}$ is considerably lower than the $\sim 6000 \mathrm{Gt}$ obtained after 100 year spin-up of CM2G (MA10). However, as further discussed below, the high global iceberg mass in $\mathrm{CM} 2 \mathrm{G}$ is associated with excessive calving rates in the Pacific sector of Antarctica (see Fig. 9a in MA10). For southern hemispheric regions where observations are available, total iceberg mass in NEMO-ICB appears to be realistic: $\sim 200 \mathrm{Gt}$ north of $66^{\circ} \mathrm{S}$ in the Southern Ocean (dashed red line in Fig. 1) compares favourably with estimates based on satellite observations over 2002-2010 (Tournadre et al., 2012, their Figs. 5 and 6).

Global iceberg mass budgets for NEMO-ICB and CM2G are summarized in Table 2. Both models are close to a balance between calving and melting, with the imbalances (net melting) just under $5 \mathrm{Gt} \mathrm{year}^{-1}$ for both simulations, corresponding to 0.37 and $0.19 \%$ of the total calving rates in NEMO-ICB and CM2G, respectively. In spite of adopting the same parameterizations as MA10, we obtain somewhat different global rates and partitioning (see Table 2). As in CM2G, wave erosion flux is dominant in NEMO-ICB, but basal melt flux is less substantial (17.27\% in NEMO-ICB, compared to $29.21 \%$ in $\mathrm{CM} 2 \mathrm{G}$ ), which may be due to different SST and wind speeds in the forced ORCA025 run compared to the fully coupled CM2G. Sidewall melting (buoyant convection) is similarly negligible in both models. For the $\mathrm{SH}$, averaged over years $26-30$, total melting of icebergs is $1128.5 \mathrm{Gt} \mathrm{year}^{-1}$. This almost exactly balances total Antarctic calving of $1140 \mathrm{Gt} \mathrm{year}^{-1}$, and is partitioned as follows: wave erosion of $918.44 \mathrm{Gt} \mathrm{year}^{-1}$ (81.4\% of the total), basal melting of $205.68 \mathrm{Gt} \mathrm{year}^{-1}(18.2 \%)$, and sidewall melting of $4.37 \mathrm{Gt} \mathrm{year}^{-1}(0.4 \%)$.

Compared to NEMO-ICB, Bigg et al. (1997) noted similar magnitudes and partitioning in the North Atlantic and Arctic, although a later version of the model featured enhanced basal melting (Gladstone et al., 2001). We might expect a greater difference in partitioning between the North Atlantic, dominated by wave erosion, and the Arctic, where basal melting should be enhanced in the presence of a relatively warm Atlantic layer (at around $100 \mathrm{~m}$ in many places). However, surface temperatures are used here in the basal melting parameterization of NEMO-ICB, which may limit basal melting in the Arctic, where surface temperatures are close to the freezing point during most of the year. A sensitivity of basal melting rates to temperature is evident in an experiment using one of our prototype modifications: when melting rates are computed with the 3-D temperature field (see Sect. 4.3), basal melting in the Southern Ocean accounts for an increased proportion of the total iceberg melting rate, from 18.2 to $29.1 \%$. 
Table 2. Global iceberg mass balances in NEMO-ICB (year 26-30 averages) and CM2G (100-year averages).

\begin{tabular}{llrr}
\hline Fluxes $\left(\mathrm{Gt} \mathrm{year}^{-1}\right)$ & & CM2G & NEMO-ICB \\
\hline Total fluxes & calving & 2210.0 & 1327.9 \\
& melting & 2214.3 & 1332.8 \\
\hline Net flux (calving-melting) & & -4.3 & -4.9 \\
\hline Components of melt flux & wave erosion & $1550.0(70.00 \%)$ & $1097.1(82.32 \%)$ \\
(and \% contribution) & basal melting & $646.8(29.21 \%)$ & $230.2(17.27 \%)$ \\
& sidewall melting & $17.5(0.79 \%)$ & $5.5(0.41 \%)$ \\
\hline
\end{tabular}
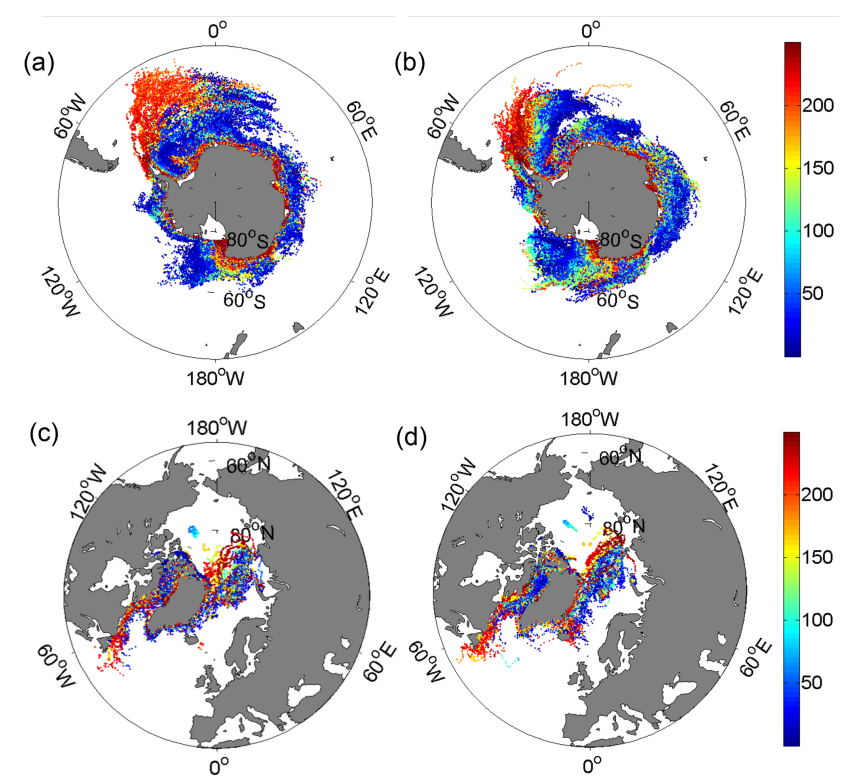

(d)

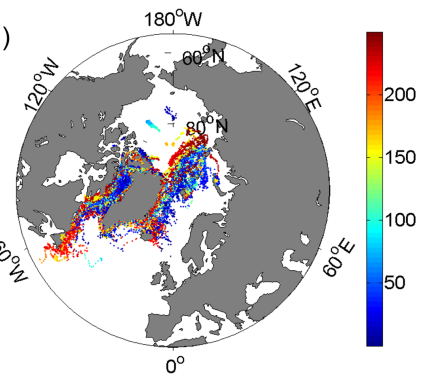

Figure 2. All iceberg positions, colour-coded for size class (or thickness), for the two seasons of year 30 in each hemisphere: (a) SH, January-June; (b) SH, July-December; (c) NH, JanuaryJune; (d) NH, July-December.

As an example of simulated iceberg drift patterns, Fig. 2 shows daily iceberg positions, colour-coded for size class (or thickness), for the two seasons of year 30 in each hemisphere (see also Fig. S1 in the Supplement for the corresponding number of icebergs and average iceberg thickness on the ORCA025 grid). Evaluation of these drift patterns is rather qualitative in the absence of corresponding observational data (except for giant icebergs), but the southern hemispheric distribution patterns compare favourably with maps of average probability, length and volume of icebergs, based on altimetry data (Tournadre et al., 2012, their Fig. 4).

In the SH (Fig. 2a, b), large icebergs (thickness $>200 \mathrm{~m}$ ) cluster along most of Antarctica, with smaller icebergs (thickness $<50 \mathrm{~m}$ ) generally found farther offshore. Large icebergs spread further equatorward in the north part of the Weddell Gyre, east of the Antarctic Peninsula to about $30^{\circ} \mathrm{E}$. To a lesser extent, large icebergs also reach the Southern
Ocean in the Indian Ocean sector at around $60^{\circ} \mathrm{E}$, and south of New Zealand, from around 150 to $180^{\circ} \mathrm{E}$. Icebergs may initially drift equatorwards due to topographically induced distortions of the ACoC, subsequently following the periphery of subpolar gyres to reach the Antarctic Circumpolar Current, where they melt rapidly. There is also a degree of seasonality in iceberg distribution, with more extensive and equatorward distributions in the austral summer/autumn (January-June), likely due to the retreat of sea ice and disappearance of an associated drag force in the iceberg momentum balance.

In the NH (Fig. 2c, d), highest iceberg concentrations are located to the west of Greenland, in Nares Strait and Baffin Bay, and north of Greenland and around Ellesmere Island. The majority of the icebergs follow the Labrador Current and are fully melted within the vicinity of the Grand Banks. As for the SH, there is a degree of seasonality in iceberg distributions. During July-December, icebergs are present in large numbers just to the north of Iceland (while largely absent in January-June), and larger icebergs are evident in the East and West Greenland currents around Cape Farewell. As calving rates are constant year round, these differences are due to seasonal variations in the dynamics and thermodynamics of icebergs.

For comparison with observations, in the northwest Atlantic we consider monthly counts of iceberg numbers observed south of $48^{\circ} \mathrm{N}$ (see Bigg et al., 2014a, and references therein), compiled by the United States Coast Guard since 1913, with earlier reports to the US Hydrographic Service extending the record back to 1900 . This record is characterized by a strong, and regular, seasonal cycle (see Fig. 2 in Bigg et al., 2014a), with a pronounced peak in numbers from spring to early summer. Bigg et al. (2014a) explain this as a combination of seasonal peaks in discharge, a delay effect from the release of icebergs being trapped in winter sea ice, and varying travel paths. Considering the iceberg drifts in Fig. $2 \mathrm{c}$ and d, we find an annual total of 40 icebergs south of $48^{\circ} \mathrm{N}$, with 19 (21) recorded as crossing this latitude during January-June (July-December). This is a considerably smaller count than the long-term observed annual total of $\sim 400$ icebergs (Bigg et al., 2014a), although we note strong inter-annual variability in the observed record. The near ab- 

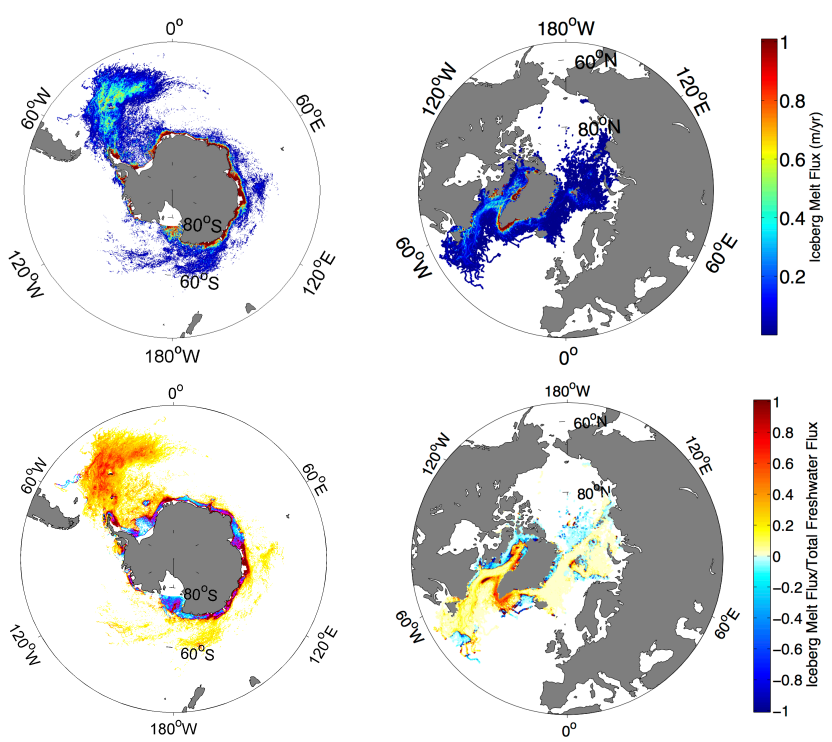

Figure 3. Iceberg total freshwater flux (year 26-30 average): total flux $\left(\mathrm{m} \mathrm{year}^{-1}\right)$ - upper panels; fractions $(-1<0<1)$ of iceberg freshwater flux to total freshwater input - lower panels.

sence of a seasonal cycle in NEMO-ICB is consistent with our use of a constant calving rate.

Figure 3 shows spatial distributions of the total freshwater fluxes due to iceberg melting, averaged over years 2630 (upper panels), alongside these fluxes as fractions of the net freshwater flux (other than iceberg melting) associated with local imbalances of precipitation and evaporation $(P-$ $E)$, runoff, and sea ice growth and melt (lower panels). Equatorward of $66^{\circ} \mathrm{S}$ in the Southern Ocean, melting patterns (and amplitudes) bear favourable comparison with estimates based on satellite observations (Tournadre et al., 2012, their Fig. 16). Notably devoid of substantial iceberg melting is the sector $60-120^{\circ} \mathrm{W}$, consistent with relatively few calving sites between the Bellingshausen Sea and the tip of the Antarctic Peninsula, while the ACoC carrying icebergs westward in this sector is strongly constrained to follow coastal topography and there is relatively limited offshore transport of icebergs into warmer waters. In the $\mathrm{NH}$, high melting rates are limited to the periphery of Greenland and the offshore Labrador Current, with very weak melting rates in the Arctic and elsewhere.

As a fraction of total freshwater input, iceberg melting exceeds 1.0 at many locations in the coastal zone of Antarctica, and around southern Greenland, where melting rates are clearly high. The fraction exceeds 0.5 in a broad southwest Atlantic swathe of the Southern Ocean. The net freshwater flux in this region is otherwise dominated by precipitation, so we can conclude that iceberg melting locally reaches around $50 \%$ of the precipitation rate. MA10 simulate a lower melting rate in this region, consistent with the location of most iceberg melting closer to Antarctica in $\mathrm{CM} 2 \mathrm{G}$, where the freshwater flux associated with sea ice melt dominates to-
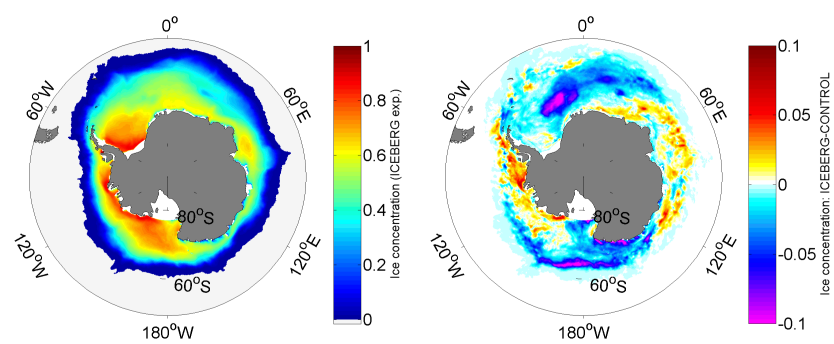

Figure 4. Annual-mean southern hemispheric sea ice concentration averaged for years 26-30, in ICEBERG (left panel), and ICEBERG minus CONTROL differences (right panel).
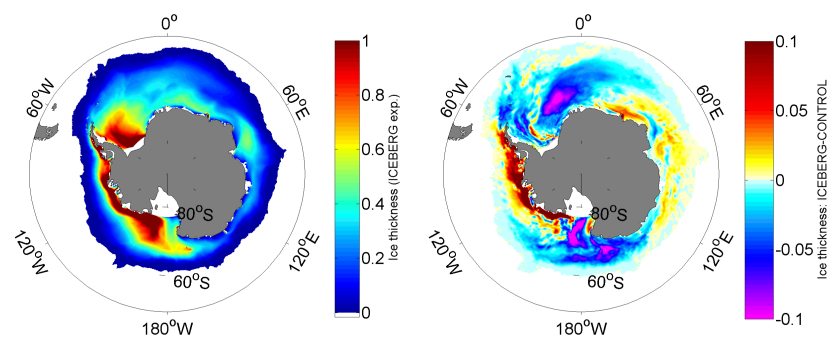

Figure 5. As Fig. 4, for sea ice thickness (defined here as the mean ice thickness of the ice-covered part of a grid cell).

tal freshwater flux (see Figs. 2a and 10 in MA10). In some regions of NEMO-ICB, iceberg melting as a fraction of net freshwater flux is negative, as the net freshwater flux is locally reversed (iceberg melting cannot be negative). This is most evident in the Weddell Sea and the Ross Sea, associated with local dominance of sea ice freezing over melting through the seasonal cycle. At some locations, the ratio exceeds -1 , indicating that iceberg melting dominates the negative freshwater flux due to sea ice freezing, and there is overall net freshening.

\subsection{Impacts on sea ice}

With a focus on southern hemispheric sea ice, we first evaluate CONTROL, with reference to very similar findings in Megann et al. (2014). Hindcast ORCA025 runs presently underestimate overall annual mean sea ice thickness around Antarctica by a moderate $15 \%$ in comparison with the Antarctic Sea Ice Processes and Climate (ASPeCt) data for the period 1996-2005 (Worby et al., 2008). The seasonal cycle of the sea ice thickness in the model is, however, in good agreement with these observations: maximum austral summer (December-February) sea ice thickness of about $1.06 \mathrm{~m}$ in the model compares to $1.02 \mathrm{~m}$ in the observations, while minimum austral winter (June-August) thickness of $0.58 \mathrm{~m}$ in the model compares to $0.60 \mathrm{~m}$.

Comparing model sea ice concentrations in the Southern Ocean with data from the Hadley Centre Sea Ice and Sea Surface Temperature (HadISST) observational data set (Rayner et al., 2003), winter sea ice distribution in hindcast 

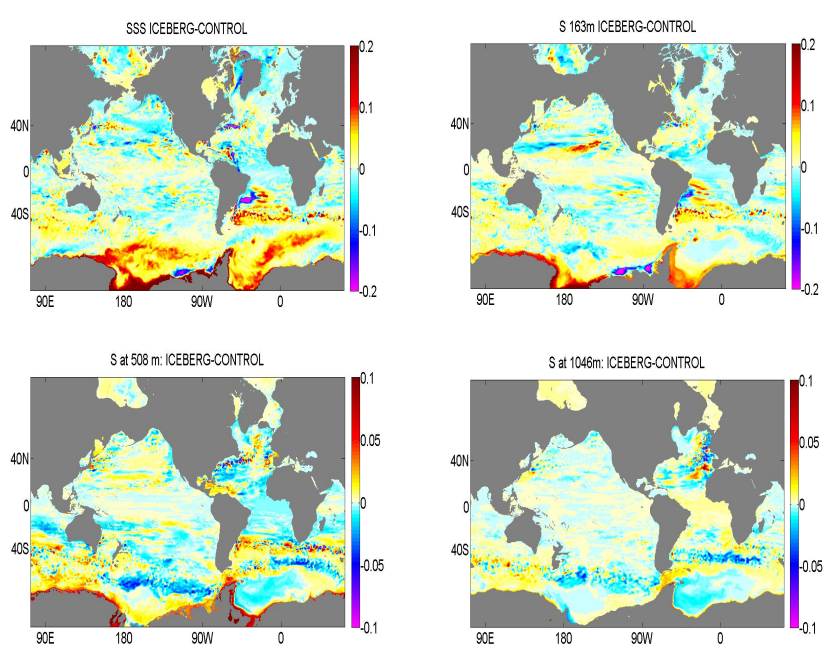

Figure 6. Changes in the global fields of salinity at selected depth levels (surface, 163, 508, $1046 \mathrm{~m}$ ), averaged over years 26-30.

ORCA025 runs is realistic, although summer sea ice concentrations are somewhat lower than in the data. Lower summer sea ice concentration in the Southern Ocean is a known bias in most forced models, and is attributed to regional uncertainties in the reanalysis fields (see discussion in Megann et al., 2014).

Icebergs substantially influence sea ice distribution, thickness and total mass. Changes are most evident in the SH. Figures 4 and 5 show year 26-30 means for ICEBERG, and differences relative to CONTROL, in southern hemispheric sea ice concentration and thickness. Including icebergs, concentration and thickness are notably decreased at most locations around Antarctica. In parts of the eastern Weddell Sea, concentration decreases by up to $\sim 20 \%-$ e.g. at around $25^{\circ} \mathrm{W}, 70^{\circ} \mathrm{S}$, concentration decreases from $\sim 0.6$ in $\mathrm{CON}-$ TROL to $\sim 0.5$ in ICEBERG - with more limited increases, of up to $\sim 10 \%$ in the Bellingshausen Sea. At locations of maximum thickness difference in the eastern Weddell and central Ross seas, annual-mean thicknesses of $\sim 50-100 \mathrm{~cm}$ in CONTROL are reduced by $\sim 10 \mathrm{~cm}$ in ICEBERG. Conversely, sea ice of thickness $\sim 100 \mathrm{~cm}$ thickens by $\sim 10 \mathrm{~cm}$ throughout the Bellingshausen and Amundsen seas, as far as the eastern Ross Sea and along the western Antarctic Peninsula.

Considering the combined effect of net reductions in annual-mean concentration and thickness in the $\mathrm{SH}$, the total mass of sea ice (averaged over years 26-30) of $4.715 \times 10^{15} \mathrm{~kg}$ in CONTROL (ICEBERG) is decreased by $2.9 \%$ in ICEBERG. Following the energy budget of MA10, we take the latent heat of fusion of water $\left(334 \times 10^{3} \mathrm{~J} \mathrm{~kg}^{-1}\right)$, and consider a notional southern hemispheric sea ice area of $10^{13} \mathrm{~m}^{2}$. The sea ice volume decrease in ICEBERG, interpreted as a consequence of differences in the annual cycle compared to CONTROL, thus equates to additional en-
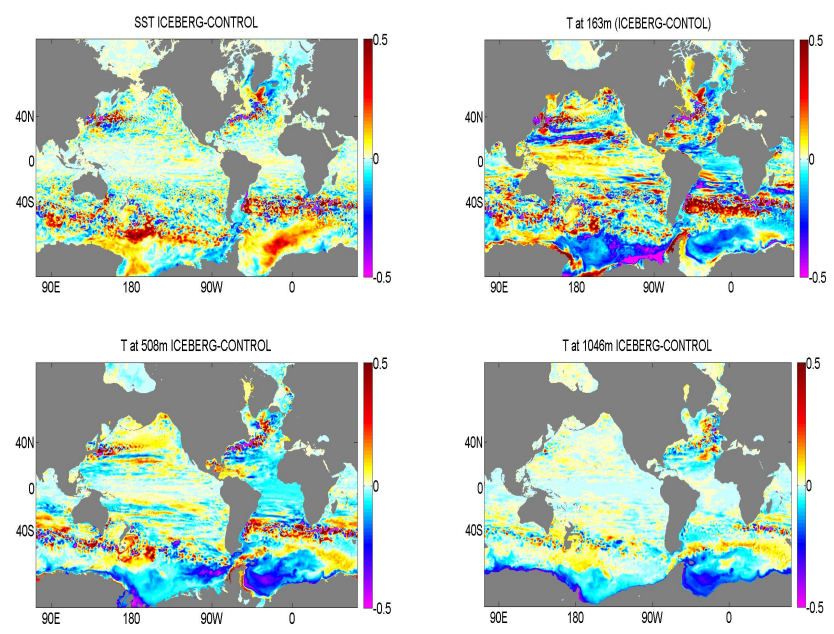

Figure 7. As Fig. 6, for potential temperature.

ergy uptake of $0.14 \mathrm{~W} \mathrm{~m}^{-2}$, which is an order of magnitude smaller than the corresponding uptake in MA10.

Generally speaking, sea ice concentration and thickness are decreased (increased) in regions where surface salinity is higher (lower) in ICEBERG (see Sect. 3.3), consistent with sea ice formation responding to the strength of the halocline - a direct thermodynamic iceberg influence on sea ice. Local coincidence of changes of sea ice thickness and concentration also suggests an indirect effect of icebergs on internal sea ice dynamics, in turn related to changes in upper ocean stratification. We infer that the presence of icebergs thus reduces sea ice convergence in much of the Weddell and Ross seas. In the Bellingshausen and Amundsen seas, sea ice drift is westward (along shore) and divergent (e.g. Holland and Kwok, 2012). In these regions, icebergs thus appear to reduce the divergence of sea ice transport, conversely increasing ice thickness and concentration.

Decreased sea ice concentration and thickness in ICEBERG is consistent with decreases at most affected grid points in the coupled atmosphere-ocean model of MA10. In the Greenland/Arctic area, the presence of icebergs leads to only minor re-distributions of sea ice concentration and thickness (not shown).

\subsection{Impacts on hydrography}

Figures 6 and 7 show ICEBERG differences, relative to CONTROL, in the global fields of salinity and potential temperature at selected depth levels (surface, 163, 508, $1046 \mathrm{~m}$ ), averaged over years $26-30$, thus accounting for short-term differences associated with transient eddies that are excited by icebergs. Given the relatively short experiments, an important caveat is that differences are likely to be less equilibrated as depth increases.

The most striking hydrographic impact of icebergs is increased surface salinity at southern high latitudes (Fig. 6). 

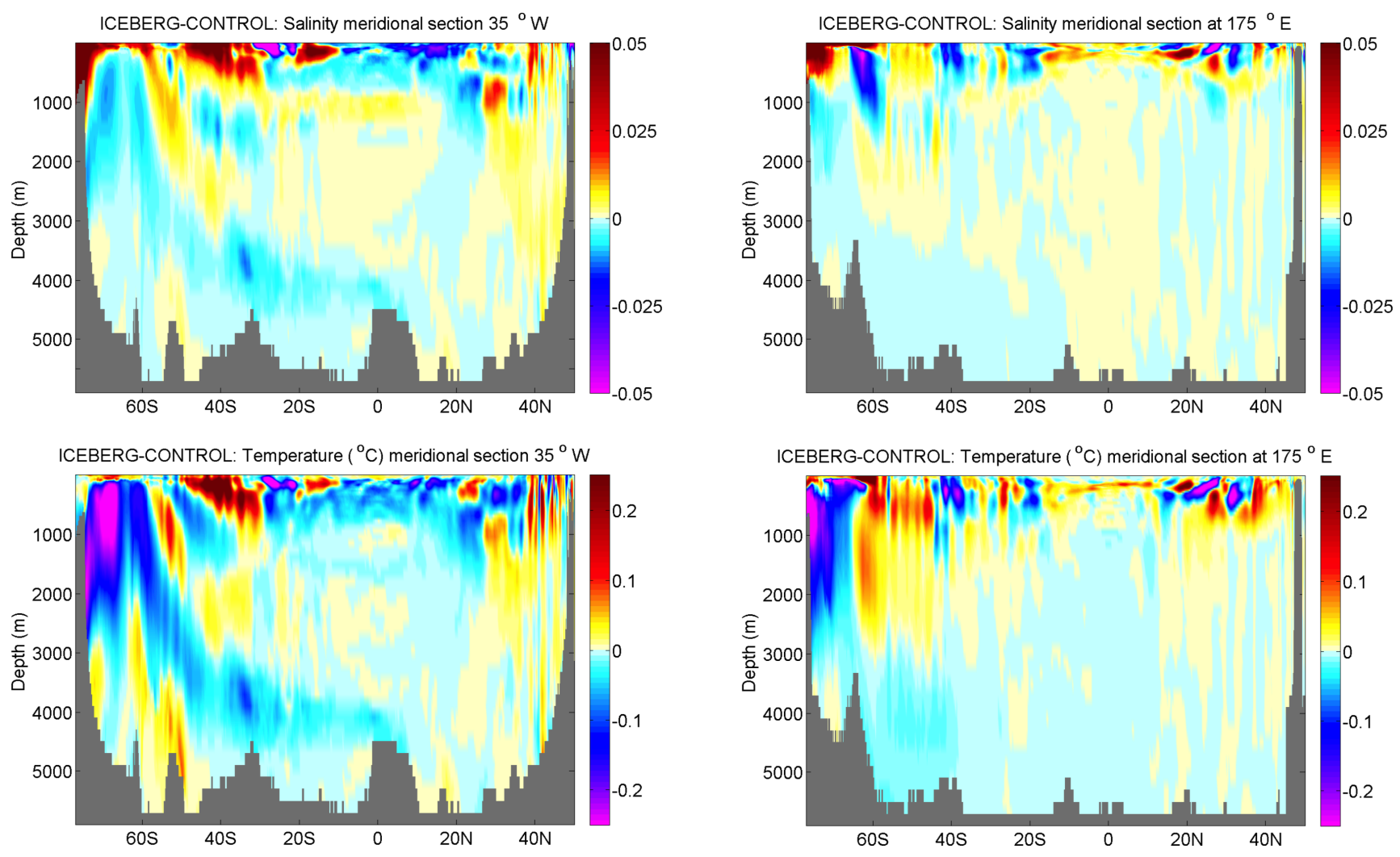

Figure 8. Meridional transect along $35^{\circ} \mathrm{W}$, showing changes in salinity (upper panel) and temperature (lower panel), averaged over years 26-30.

Differences are strongly positive immediately adjacent to Antarctica ( $>0.2 \mathrm{psu}$ at most longitudes), where runoff is substantially reduced (in proportion to the specified calving flux), but salinity differences also exceed 0.05 across broad swathes of the high-latitude Southern Ocean. Salinity in ICEBERG is notably increased in regions where annual-mean sea ice concentration and thickness is strongly reduced (see Figs. 4 and 5). This suggests that differences in the seasonal cycle of sea ice freezing, export and melting contribute substantially to the increases of surface salinity in ICEBERG.

Weaker negative differences are coincident with the locally strong iceberg melting "plume" to the east of the Antarctica Peninsula, in the Atlantic sector of the Southern Ocean (see Fig. 3). More distinct negative differences are coincident with the highest concentration of Greenland icebergs, around Davis Strait. With increasing depth, negative differences are more evident in southern high latitudes, and are extensive throughout the Weddell Sea at 508 and $1046 \mathrm{~m}$.

Temperature differences are also substantial. At the surface, positive differences are extensive at southern high latitudes, again coincidental with differences in sea ice concentration and thickness. A simple explanation is that surface temperatures are higher due to stronger surface ocean heat gain where sea ice is thinner and/or absent for more

Figure 9. As Fig. 8, at $175^{\circ}$ E.

of the year. Large differences are also evident sub-surface, with widespread negative differences in the Atlantic and Pacific sectors of the high-latitude Southern Ocean. In the Weddell Sea, where particularly large negative differences extend to great depth (e.g. $\sim 1000 \mathrm{~m}$ ), we can conclude that a thin warmer, more saline layer lies above an otherwise cooler, fresher water column. This implicit re-partitioning of heat and freshwater is associated with locally reduced sea ice concentration and thickness.

Substantial salinity and temperature differences are also evident at lower latitudes, such as in the South Atlantic to at least $\sim 500 \mathrm{~m}$, with broader freshening and cooling of the tropical and subtropical Atlantic at this depth. At all four selected depth levels, large salinity and temperature differences are also evident near strong currents such as the Antarctic Circumpolar Current, and western boundary currents such as the Gulf Stream and Kuroshio. We show in Sect. 3.5 that such differences are also associated with changes in ocean currents.

Informed by differences on selected levels in Figs. 6 and 7, in Figs. 8 and 9 we show salinity and temperature differences along selected meridional transects, at $35^{\circ} \mathrm{W}$ and $175^{\circ}$ E (see also Figs. S2-S5 in the Supplement for transects with an expanded vertical scale in the upper $1000 \mathrm{~m}$ ). In both Figs. 8 and 9, the deepest extent of negative salinity and temperature differences is clearly located at high south- 


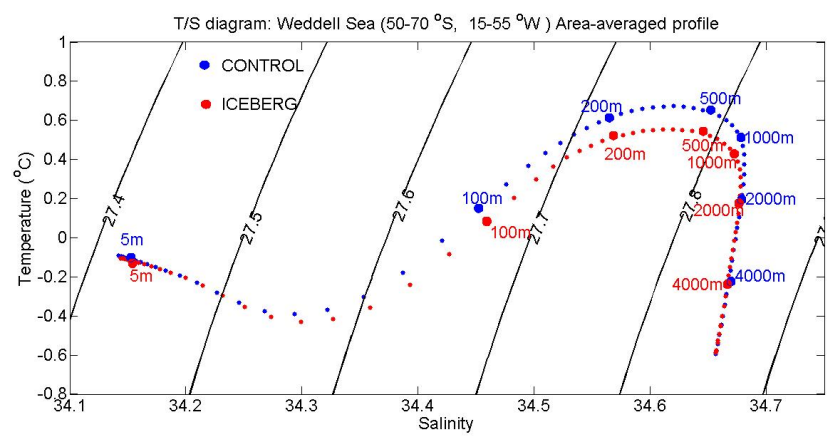

(a)

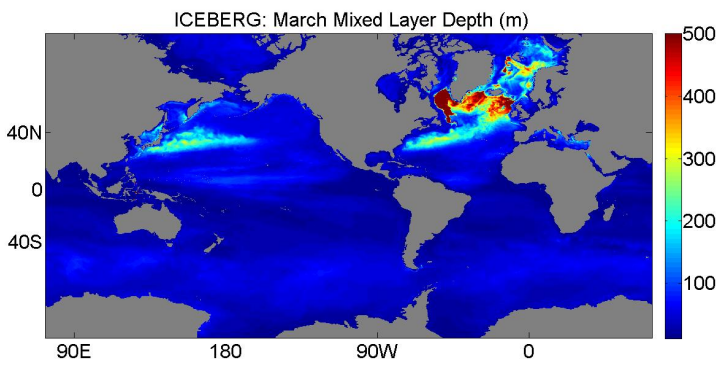

(b)
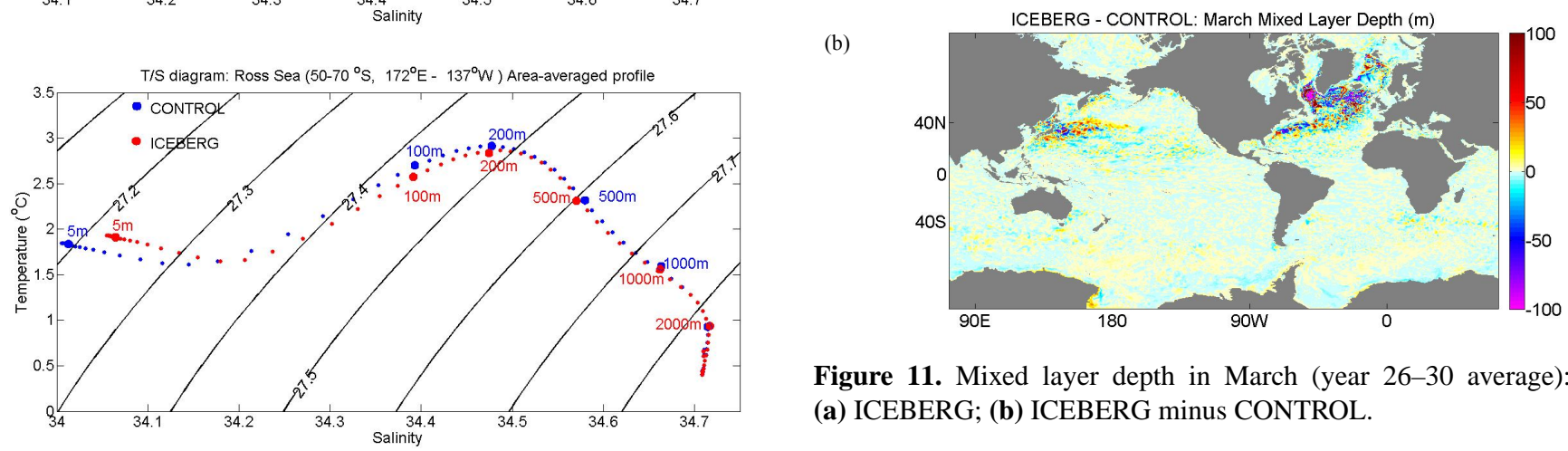

Figure 10. Area-averaged $T / S$ diagrams representative of the Weddell Sea $\left(50-70^{\circ} \mathrm{S}, 15-55^{\circ} \mathrm{W}\right.$; upper panel) and the Ross Sea (50$70^{\circ} \mathrm{S}, 172^{\circ} \mathrm{E}-137^{\circ} \mathrm{W}$; lower panel), for ICEBERG (red points) and CONTROL (blue points).

ern latitudes. In the Weddell Sea of ICEBERG, negative differences of up to $0.01 \mathrm{psu}$ - below $100-200 \mathrm{~m}$ - extend to around $2000 \mathrm{~m}$. In Fig. 8, it is evident that Antarctic Intermediate Water (AAIW) in ICEBERG is fresher by up to 0.01 (around $40^{\circ} \mathrm{S}, 1300 \mathrm{~m}$ ). This fresh signal may be traced back to the region of iceberg melting east of the Antarctic Peninsula, and may be a transient signal of locally more dominant iceberg melting earlier in the hindcast, noting that the positive surface salinity differences progressively spread northward from the coastal zone of Antarctica over years 21-30 (not shown).

To show how temperature and salinity change in relation to density, for selected regions where iceberg influences are strongest, Fig. 10 shows area-averaged $T-S$ (temperaturesalinity) diagrams for the Ross Sea/Pacific and Weddell Sea/Atlantic sectors (both south of $50^{\circ} \mathrm{S}$, excluding all grid points near the coast). An overall impression (upper panels) is that ICEBERG salinities (red points) are mostly shifted to lower salinity below around $300 \mathrm{~m}$, by up to 0.01 psu relative to CONTROL salinities (blue points). Area-averaged differences are generally not temperature compensated at upper levels (above $\sim 500 \mathrm{~m}$ ), leading to ICEBERG density increases (shifts across isopycnals) on depth levels in the upper $500 \mathrm{~m}$, reaching maxima of $\sim 0.015 \mathrm{~kg} \mathrm{~m}^{-3}$ at $\sim 100 \mathrm{~m}$ and $\sim 0.030 \mathrm{~kg} \mathrm{~m}^{-3}$ at $5 \mathrm{~m}$, in the Weddell Sea and Ross Sea, respectively. Below $\sim 1000 \mathrm{~m}$, changes of salinity and temperature are very close to density compensating, although

there are, on average, slight density decreases in ICEBERG at around $4000 \mathrm{~m}$ in the Weddell Sea and at around $500 \mathrm{~m}$ in the Ross Sea. These density changes will potentially influence dense water formation and the global abyssal circulation in a longer simulation.

Averaged over years 26-30, global volume-averaged salinity is $0.00025 \mathrm{psu}$ higher in ICEBERG compared to CONTROL, while for the Antarctic region (south of $50^{\circ} \mathrm{S}$ ), volume-averaged salinity is $0.0015 \mathrm{psu}$ higher in ICEBERG. By contrast, in the North Atlantic (north of $50^{\circ} \mathrm{N}$ ) volume-averaged salinity is around 0.0010 lower in ICEBERG. These very small differences are within the interannual variations of global-mean and regional-mean salinity, and confirm that the prescribed freshwater fluxes in $\mathrm{CON}$ TROL and ICEBERG are identical.

\subsection{Impacts on mixed layer depth}

Related to their widespread impact on the seasonal evolution of salinity and temperature, icebergs exert an influence on end-of-winter MLDs. Figures 11 and 12 show global fields of average March and September MLD, in ICEBERG and the difference from CONTROL, averaged over years 26-30. In March (Fig. 11), areas of greatest MLD (>500 m) in the North Atlantic are generally shallower in ICEBERG by up to $100 \mathrm{~m}$ (purple shading in Fig. 11b), notably in the central Labrador Sea, and in patches north and south of Iceland. Conversely, in the western subtropics of the North Pacific, MLDs of up to $250 \mathrm{~m}$ in ICEBERG are in many places around $25 \mathrm{~m}$ deeper than in CONTROL.

In September (Fig. 12), deep mixed layers in the Pacific sector of the Southern Ocean are most strongly affected by 
(a)

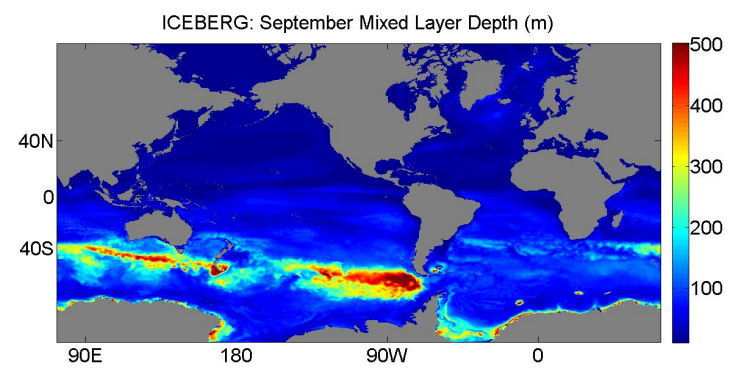

(b)

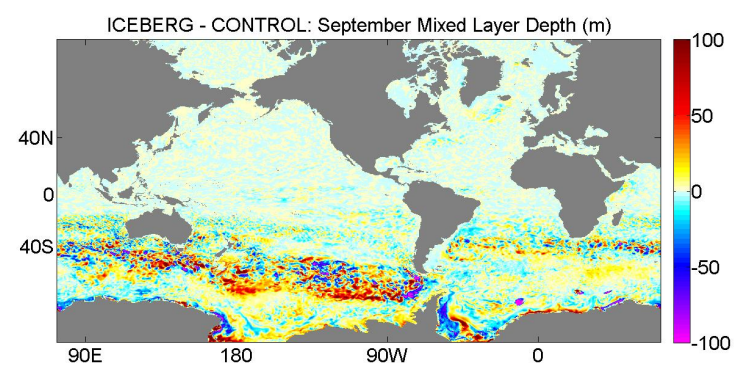

Figure 12. Mixed layer depth in September (year 26-30 average): (a) ICEBERG; (b) ICEBERG minus CONTROL.

icebergs. From $180^{\circ} \mathrm{E}$ to around $90^{\circ} \mathrm{W}$, in the zone 50 $65^{\circ} \mathrm{S}$, ICEBERG MLDs in the range $200-400 \mathrm{~m}$ are generally deeper than those in CONTROL, by around $50 \mathrm{~m}$ at many locations. This can be related to hydrographic changes. North of $\sim 60^{\circ} \mathrm{S}$ in the Southern Ocean, we conjecture that increased surface salinity in ICEBERG (see Fig. 6) is mostly driven by the weaker re-distribution of freshwater by sea ice, which is a first-order mechanism for transporting freshwater northward in the Southern Ocean and contributes to the fresh signature of AAIW. In ICEBERG, reductions in sea ice concentration and thickness (Figs. 4 and 5) are indicative of reduced northward transport of (thinner) sea ice, with sea ice melting shifted southward. This appears to have a large impact on subducting AAIW properties (see Fig. 8) and local MLD, as outlined above. We also note substantial changes close to Antarctica, notably in the western sectors of the Weddell and Ross seas, where MLDs of 100-200 $\mathrm{m}$ in ICEBERG are up to $50 \mathrm{~m}$ shallower than in CONTROL.

\subsection{Impacts on ocean currents}

To quantify the mean strength of ocean currents, we take the time average of kinetic energy (KE), here simply defined as $\left(u^{2}+v^{2}\right) / 2$ where $u$ and $v$ are the zonal and meridional components of the ocean current, at selected depths. The difference of $\mathrm{KE}$ is calculated from currents averaged over years 26-30 in ICEBERG relative to CONTROL $(\Delta \mathrm{KE})$, and shown in Fig. 13 at three levels, 61, 163 and $508 \mathrm{~m}$ (the deeper levels coincident with levels chosen to show property changes).

Starting in the region most directly impacted by repartitioning of freshwater fluxes, we find negative near- (a)

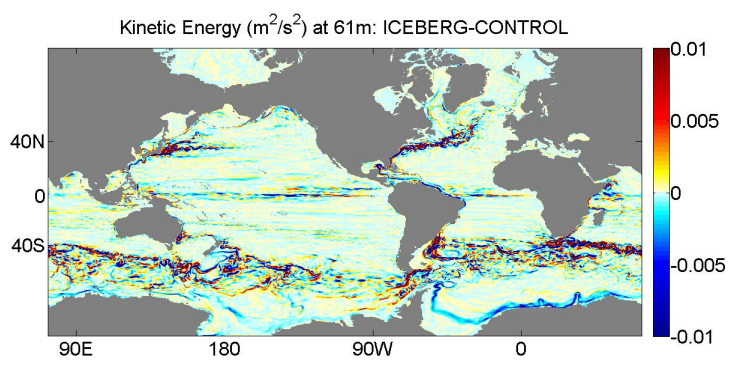

(b)

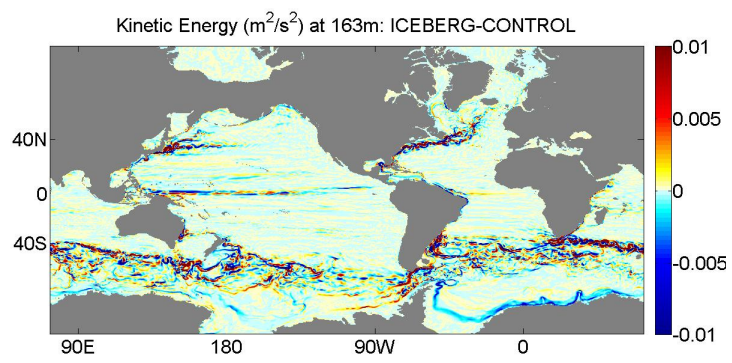

(c)

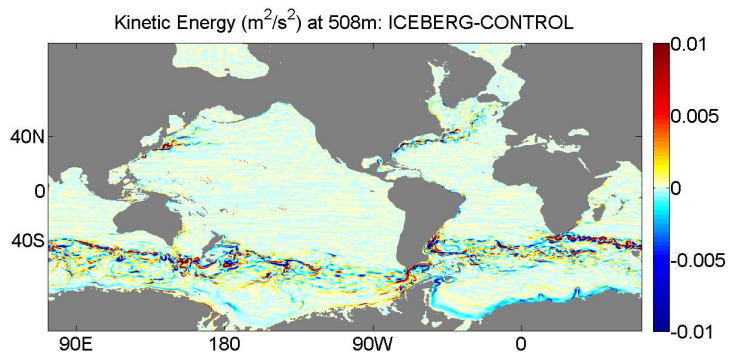

Figure 13. Differences (ICEBERG minus CONTROL) in the year 26-30 time average of kinetic energy (KE) at (a) $61 \mathrm{~m}$; (b) $163 \mathrm{~m}$; (c) $508 \mathrm{~m}$.

surface $\triangle \mathrm{KE}$ values at all depths of the ACoC that skirts Antarctica, particularly in the Atlantic sector. This indicates a weaker baroclinic component of the ACoC in ICEBERG, due to changes in the cross-shelf density gradients (low to high density moving cross shelf) that drive an eastward flow component of the $\mathrm{ACoC}$ via the thermal wind balance (NúñezRiboni and Fahrbach, 2009, 2010). The ACoC is a primarily wind-driven westward current (Hayakawa et al., 2012), so the thermal wind component in ICEBERG more strongly opposes the largely unchanged westward component. We note that wind forcing can possibly increase with reduced sea ice concentration, but this effect is likely to be small. The stronger thermal wind would be consistent with particularly strong offshore cooling at, e.g. 163 and $508 \mathrm{~m}$, indicated in Fig. 7.

More remote from Antarctica, we find high near-surface $\triangle \mathrm{KE}$ values in the Antarctic Circumpolar Current, associated in particular with major topographic features near South America and South Africa. Substantial $\triangle K E$ values are also evident further afield, in equatorial regions, and aligned with the cores of the separated boundary currents 
(up to $0.05 \mathrm{~m}^{2} \mathrm{~s}^{-2}$ ) - notably the Gulf Stream and Kuroshio currents. The substantial and coherent area of $\triangle \mathrm{KE}$ in the Kuroshio, persistent over the 5-year averaging period, corresponds to an increase in the central meandering jet, and a decrease in the south part of this jet.

A more detailed view of the Gulf Stream region is provided in Fig. S6 in the Supplement. The spatial structure of $\triangle \mathrm{KE}$ is coherent with depth, between the surface and 200 $300 \mathrm{~m}$, but differences rapidly decline below $300 \mathrm{~m}$. Temperature differences averaged over years 26-30 (see Fig. 7) are spatially coherent on large scales in the vicinity of boundary currents. For example, considering negative differences in excess of $-0.5^{\circ} \mathrm{C}$, a substantial cold anomaly is apparent to the north of the Gulf Stream at $508 \mathrm{~m}$. We conclude here that property differences throughout the global ocean are to an extent associated with systematic changes in ocean currents. In the relatively short simulations here, these remote changes (in properties and currents) must be excited by rapid propagation of density anomalies from high to low latitudes, a mechanism discussed briefly in Sect. 5 .

\section{Prototype modifications of NEMO-ICB}

While we have focused so far on a baseline simulation with NEMO-ICB, three modifications of the iceberg model have been most recently implemented and are currently being tested in a slightly different ORCA025 configuration. These modifications will possibly be included in future code releases and are therefore only briefly described and discussed below.

\subsection{Advection of icebergs with vertically integrated ocean velocity}

Icebergs in the real world are influenced by the vertical shear of ocean currents. In particular, Ekman drift is suspected to affect iceberg trajectory. In a first modification of the baseline code, the depth-averaged ocean velocity is used in place of surface currents for advecting icebergs. In practice, the ocean velocity value used by the iceberg dynamics solver corresponds to the depth-averaged ocean velocity between the surface and the deepest tracer grid-point reached by the iceberg. Preliminary results suggest that iceberg trajectories are sensitive to this modification. Iceberg movements are locally less erratic, being less affected by high-frequency fluctuations of surface currents and winds. The large-scale distribution of icebergs, especially in the Southern Ocean, also appears to be affected by this modification.

\subsection{Iceberg interaction with shallow bathymetry}

The thickness of bigger icebergs in the model is not negligible in comparison to the bathymetry of several coastal regions in the ORCA025 configuration. Is also known that big icebergs can get stuck on shallow bathymetry around Antarc- tica, where they stay for long periods of time before moving northwards. Furthermore, using depth-integrated currents for advecting icebergs also requires accounting for how icebergs interact with shallow bathymetry (where depth-averaged currents can be ill-defined). Fully accommodating this interaction with shallow bathymetry in the iceberg model could be complicated and computationally expensive. Indeed, in the model, Lagrangian particles represent a collection of icebergs with identical parameters, but physically we do not expect the bathymetry to "stock" more than one iceberg at the same time. We therefore tested two simpler options for handling iceberg interaction with shallow bathymetry, although comparison with observations remains largely qualitative. These options are outlined as follows:

- Option A: shallow bathymetry points are considered as islands. With this modification, icebergs tend to travel around shallow regions, or eventually get stuck when no escape is possible, until melting enough to cross the shallow region.

- Option B: icebergs proceed across shallow bathymetry, even if their thickness exceeds the local depth. In this case, the iceberg drift velocity is computed from depthaveraged ocean currents (see Sect. 4.1), which now include masked values (zero currents) at model depth levels below the seabed. With this choice, icebergs are slowed down over shallow bathymetry but can still transit through shallow regions.

Preliminary results suggest that the differences between the two options appear not globally very important in the long term, but further work and longer simulations are needed. However, we see more remarkable differences of individual trajectories close to coastal areas.

\subsection{Melting rates computed with the 3-D temperature field}

To further resolve vertical physics in the model, we are also testing modifications for computing melting rates from the 3-D ocean temperature field. All three components of melt rate in the baseline version of ICB depend on surface temperature, and are reconsidered/modified accordingly:

- Basal melting: in our 3-D modification, we consider instead the temperature at the maximal depth reached for each iceberg.

- Buoyant convection at the sidewalls: this is a quadratic temperature-dependent function; in our 3-D modification, this function is integrated between the surface and the maximum depth of each iceberg.

- Wave erosion: this depends only on surface temperature; hence, we do not modify this component. 
In the few cases when icebergs are at a grid point where bathymetry is shallower than the iceberg thickness, the temperature considered for the part of iceberg that is deeper than bathymetry takes the value of the deepest ocean point.

Preliminary results show that, overall, this modification leads to a slightly higher global melt rate. In the Southern Ocean, this happens mostly during the boreal autumn and winter months (from April to September) when icebergs start transiting across the Weddell and Ross seas. Icebergs therefore tend to melt faster which leads to shorter trajectories downstream in the northern Weddell and Ross seas. Incidentally, with 3-D temperature, icebergs are also less sensitive to some surface warm biases that may appear related to the stronger stratification induced by iceberg melting, but further analysis is required for more robust conclusions about this modification.

\section{Summary and discussion}

We have included icebergs interactively in an eddypermitting global configuration of the ocean model NEMO, the first time that icebergs have been implemented at this resolution. Simulated iceberg distributions and freshwater fluxes are in reasonable agreement with limited available observations, in the northwest Atlantic (Bigg et al., 2014a, and references therein) and in the Southern Ocean (Tournadre et al., 2012).

Freshwater forcing due to iceberg melting is most pronounced very locally, in the coastal zone around much of Antarctica, where it often exceeds in magnitude and opposes the negative freshwater fluxes associated with sea ice freezing. However, at most locations in the polar Southern Ocean, the annual-mean freshwater flux due to icebergs, if present, is typically an order of magnitude smaller than the contribution of sea ice and precipitation. A notable exception is the southwest Atlantic sector of the Southern Ocean, where iceberg melting reaches around $50 \%$ of net precipitation over a large area. Including icebergs, sea ice concentration and thickness are notably decreased at most locations around Antarctica, by up to $\sim 20 \%$ in the eastern Weddell Sea, with more limited increases, of up to $\sim 10 \%$, in the Bellingshausen Sea. Antarctic sea ice mass decreases by $2.9 \%$, overall.

As a consequence of changes in net freshwater forcing and sea ice, salinity and temperature distributions are also substantially altered. Surface salinity increases by $\sim 0.1 \mathrm{psu}$ around much of Antarctica, due to suppressed coastal runoff, with extensive freshening at depth, extending to greatest depths in the high-latitude Southern Ocean where discernible effects on both salinity and temperature reach $2500 \mathrm{~m}$ in the Weddell Sea by the last pentad of the simulation.

Our choice of reference run (CONTROL) has considerable bearing on the present results. Most DRAKKAR simulations with ORCA025 now use static 2-D maps of freshwater flux due to melting icebergs. Further experiments and analy- sis would be necessary to establish the impact of interactive icebergs on the model ocean, in contrast to implicit iceberg melting. A step in this direction is to preserve runoff rates around the ice sheets and ice caps. In a shorter sensitivity experiment, ICEBERG2, we re-ran the first 10 years of the hindcast with calved icebergs as in ICEBERG and runoff as in CONTROL. The icebergs in ICEBERG2 thus provide an additional freshwater flux, and the Southern Ocean (in particular) consequently freshens almost everywhere. Such an experiment provides the preliminary basis for investigating the sensitivity of the ocean to ice sheet mass imbalance.

Coherent patterns of difference in salinity and temperature develop throughout the global ocean, and ocean currents are systematically altered. Perturbations in the high-latitude density field, associated with icebergs, will propagate around the globe as Rossby and Kelvin waves. Previous model studies have shown the importance of wave-like mechanisms for communication between Antarctic and equatorial regions (e.g. Atkinson et al., 2009). In such studies, salinity anomalies in the Southern Ocean excite fast westward-propagating barotropic planetary waves (Gill, 1982), which propagate to the western boundary of the South Pacific. On arrival at the western boundary, these Rossby waves excite baroclinic Kelvin waves, which propagate more slowly to, and then along, the Equator. However, the perturbations applied in previous model studies were artificial, involving large and sustained changes in salinity over substantial portions of the Southern Ocean. In contrast to these studies, salinity and temperature differences between ICEBERG and CONTROL can be regarded as fluctuations that are more naturally associated with melting icebergs. It is also possible for the density anomalies associated with iceberg melting to directly generate baroclinic planetary waves, which can propagate similar distances, much more slowly, but with potentially larger amplitude. In conclusion, more experiments for longer periods of time are needed to better understand slower variability of the system, and the various ocean teleconnections associated with variable iceberg calving and melting.

In the context of NEMO development and evaluation, the effects of icebergs on surface property fields and mixed layer depths (MLDs) are noteworthy. Megann et al. (2014) evaluate a similar 30-year hindcast using a global eddy-permitting configuration of NEMO v3.4. Over large areas of the world oceans, SST and surface salinity errors (Fig. 1 in Megann et al., 2014) exceed $\pm 0.25^{\circ} \mathrm{C}$ and \pm 0.1 psu respectively, with SST biases of $\pm 1.0^{\circ} \mathrm{C}$ near Greenland. Based on the SST differences in Fig. 7, we suggest that the inclusion of icebergs could substantially reduce SST errors in mid- and high latitudes of the North Atlantic, although errors may be exacerbated elsewhere. Maximum MLDs in the NEMO v3.4 hindcast (Fig. 2 in Megann et al., 2014) are generally excessive. In particular, very deep mixing in the eastern Weddell Sea is regarded as unrealistic, related to reduced sea ice extent in this region. While this feature is largely absent in both CONTROL and ICEBERG, at least within the short hind- 
cast, the inclusion of icebergs may further improve realism in the subpolar North Atlantic, where we find reductions in end-of-winter MLDs of the order of $10 \%$.

The baseline representation of icebergs has been extended to represent iceberg interactions with shallow topography, and to use 3-D velocity and temperature fields to force iceberg drift and melt. We are, however, not yet vertically resolving the iceberg melting rates. Given that the size of our maximum iceberg is much less than even the ORCA025 resolution, and that buoyant plumes from iceberg basal and sidewall melting are expected to rise quickly to the surface within a few hundred metres, applying these fluxes to the surface is inherently reasonable at current model resolutions. Large icebergs may exert a more remote influence on hydrography, at distances of up to several 10s of kilometres (Stephenson et al., 2011). Melting at sufficient depth may lead to the entrainment and upwelling of relatively warm and salty Circumpolar Deep Water around large icebergs in the Southern Ocean (Jenkins, 1999). Stephenson et al. (2011) report observations of the corresponding alternative ways that ice meltwater disperses from a large tabular iceberg in the northern Weddell Sea: turbulent entrainment, localized near the iceberg, as well as wider horizontal dispersal due to double diffusive processes, as originally demonstrated in pioneering laboratory experiments (Huppert and Turner, 1980). Representation of large icebergs and these associated processes is currently beyond the capability of NEMO-ICB.

More feasible is the development of iceberg interaction with sea ice. At high sea ice concentration, icebergs tend to drift with the sea ice (Lighey and Hellmer, 2001). However, trajectories for individual giant icebergs (e.g. B31 over the austral winter of 2014 - see Bigg et al., 2014b) indicate that this only holds when the icebergs are frozen in to thick pack (essentially land-fast ice), rather than in the extensive areas where lead formation is common. More generally, we anticipate a maximum in the velocity of icebergs moved by sea ice, proportional to sea ice thickness and inversely proportional to iceberg draft (Morison and Goldberg, 2012). For sea ice moving at velocities higher than this maximum, sea ice ridging is expected, amounting to a dynamical feedback of icebergs on sea ice. In ongoing work, we have implemented solutions proposed by Hunke and Comeau (2011), and initial findings are that iceberg trajectories are sensitive to these changes.

Finally, NEMO-ICB may be used with a parameterization of ice shelf cavity melting, to more realistically represent rapidly changing mass fluxes from Antarctica to the surrounding ocean. This combined capability should underpin experiments with enhanced calving and melting rates that eventually supplant current state-of-the-art protocols for freshwater forcing (van den Berk and Drijfhout, 2014). In the longer term, it would be desirable for ocean models with this capability to be included in future experimental activities of the Coupled Model Inter-comparison Project.

\section{Code availability}

NEMO-ICB is available via the NEMO home page, where new users can register via http://www.nemo-ocean. eu/user/register. Registered users can access the ICB modules at https://forge.ipsl.jussieu.fr/nemo/browser\#trunk/ NEMOGCM/NEMO/OPA_SRC/ICB

ICB comprises the following modules:

- icb_oce.F90 - declares variables for iceberg tracking

- icbclv.F90 - calving routines for iceberg calving

- icbdia.F90 - initializes variables for iceberg budgets and diagnostics

- icbdyn.F90 - time stepping routine for iceberg tracking

- icbini.F90 - initializes variables for iceberg tracking

- icblbc.F90 - routines to handle boundary exchanges for icebergs

- icbrst.F90 - reads and writes iceberg restart files

- icbstp.F90 - initializes variables for iceberg tracking

- icbthm.F90 - thermodynamics routines for icebergs

- icbtrj.F90 - trajectory I/O routines

- icbutl.F90 - various iceberg utility routines.

Default iceberg parameters are specified at https: //forge.ipsl.jussieu.fr/nemo/browser/trunk/NEMOGCM/ CONFIG/SHARED/namelist_ref

When compiling NEMO-ICB, the flag ln_icebergs in this namelist file is set to .true.

\section{The Supplement related to this article is available online at doi:10.5194/gmd-8-1547-2015-supplement.}

Acknowledgements. We thank Torge Martin and Alistair Adcroft for providing their code as a basis for the ICB module. Funding to couple NEMO with the icebergs module was provided by the UK Natural Environment Research Council (grant number $\mathrm{NE} / \mathrm{H} 021396 / 1$ ) for the project "A century of variability in Greenland melting and iceberg calving". We are grateful to three anonymous reviewers and the topic editor for a wide range of helpful comments and insights.

Edited by: D. Goldberg 


\section{References}

Atkinson, C. P., Wells, N. C., Blaker, A. T., Sinha, B., and Ivchenko, V. O.: Rapid ocean wave teleconnections linking Antarctic sea salinity anomalies to the equatorial ocean-atmosphere system, Geophys. Res. Lett., 36, L08603, doi:10.1029/2008GL036976, 2009.

Bigg, G. R. and Wadley, M. R.: Prediction of iceberg trajectories for the North Atlantic and Arctic Oceans, Geophys. Res. Lett., 23, 3587-3590, 1996.

Bigg, G. R., Wadley, M. R., Stevens, D. P., and Johnson, J. A.: Modelling dynamics and thermodynamics of icebergs, Cold Reg. Sci. Technol., 26, 113-135, 1997.

Bigg, G. R., Wei, H. L., Wilton, D. J., Zhao, Y., Billings, S. A., Hanna, E., and Kadirkamanathan, V.: A century of variation in the dependence of Greenland iceberg calving on ice sheet surface mass balance and regional climate change, P. R. Soc. A, 470, doi:10.1098/rspa.2013.0662, 2014a.

Bigg, G. R., Marsh, R., Wilton, D., and Ivchenko, V. O.: B31 - a giant iceberg in the Southern Ocean, Ocean Challenge, 20, 32$34,2014 b$.

Fichefet, T. and Maqueda, M. A.: Sensitivity of a global sea ice model to the treatment of ice thermodynamics and dynamics, J. Geophys. Res., 102, 12609-12646, 1997.

Gill, A. E.: Atmosphere-Ocean Dynamics, Academic Press, 662 pp., 1982.

Gladstone, R., Bigg, G. R., and Nicholls, K.: Iceberg trajectory modeling and meltwater injection in the Southern Ocean, J. Geophys. Res., 106, 19903-19915, 2001.

Hayakawa, H., Shibuya, K., Aoyama, Y., Nogi, Y., and Doi, K.: Ocean bottom pressure variability in the Antarctic Divergence Zone off Lützow-Holm Bay, East Antarctica, Deep-Sea Res. Pt. I, 60, 22-31, 2012.

Holland, P. R. and Kwok, R.: Wind-driven trends in Antarctic seaice drift, Nat. Geosci., 5, 872-875, doi:10.1038/ngeo1627, 2012.

Hunke, E. C. and Comeau, D.: Sea ice and iceberg dynamic interaction, J. Geophys. Res., 116, C05008, doi:10.1029/2010JC006588, 2011

Hunke, E. C. and Lipscomb, W. H.: CICE: The Los Alamos Sea Ice Model, Documentation and Software User's Manual, Version 4.1, Tech. Rep. LA-CC-06-012, Los Alamos National Laboratory, Los Alamos, New Mexico, available at: http://oceans11. lanl.gov/trac/CICE (last access: 13 May 2015), 2010.

Huppert, H. E. and Turner, J. S.: Ice blocks melting into a salinity gradient, J. Fluid. Mech., 100, 367-384, 1980.

Jenkins, A.: The impact of melting ice on ocean waters, J. Phys. Ocean., 29, 2370-2381, 1999.

Jongma, J. I., Driesschaert, E., Fichefet, T., Goosse, H., and Renssen, H.: The effect of dynamic-thermodynamic icebergs on the Southern Ocean climate in a three-dimensional model, Ocean Model., 26, 104-113, 2009.

Levine, R. C. and Bigg, G. R.: The sensitivity of the glacial ocean to Heinrich events from different sources, as modeled by a coupled atmosphere-iceberg-ocean model, Paleoceanography, 23, PA4213, doi:10.1029/2008PA001613, 2008.
Lighey, C. and Hellmer, H. H.: Modeling giant-iceberg drift under the influence of sea ice in the Weddell Sea, Antarctica, J. Glaciol., 47, 452-460, 2001.

Madec, G.: "NEMO ocean engine". Note du Pole de modélisation, Institut Pierre-Simon Laplace (IPSL), France, No. 27 ISSN No 1288-1619, 2008.

Marsh, R., Ivchenko, V. O., Skliris, N., Alderson, S., Bigg, G. R., Madec, G., Blaker, A., and Aksenov, Y.: NEMO-ICB (v1.0): interactive icebergs in the NEMO ocean model globally configured at coarse and eddy-permitting resolution, Geosci. Model Dev. Discuss., 7, 5661-5698, doi:10.5194/gmdd-7-5661-2014, 2014.

Martin, T. and Adcroft, A.: Parameterizing the fresh-water flux from land ice to ocean with interactive icebergs in a coupled climate model, Ocean Model., 34, 111-124, 2010.

Megann, A., Storkey, D., Aksenov, Y., Alderson, S., Calvert, D., Graham, T., Hyder, P., Siddorn, J., and Sinha, B.: GO5.0: the joint NERC-Met Office NEMO global ocean model for use in coupled and forced applications, Geosci. Model Dev., 7, 10691092, doi:10.5194/gmd-7-1069-2014, 2014.

Morison, J. and Goldberg, D.: A brief study of the force balance between a small iceberg, the ocean, sea ice, and atmosphere in the Weddell Sea, Cold Reg. Sci. Technol., 76-77, 69-76, 2012.

Núñez-Riboni, I. and Fahrbach, E.: Seasonal variability of the Antarctic Coastal Current and its driving mechanisms in the Weddell Sea, Deep-Sea Res. Pt. I, 56, 1927-1941, doi:10.1016/j.dsr.2009.06.005, 2009.

Núñez-Riboni, I. and Fahrbach, E.: An observation of the banded structure of the Antarctic Coastal Current at the prime meridian, Polar Res., 29, 322-329, doi:10.1111/j.17518369.2010.00166.x, 2010.

Rayner, N. A., Parker, D. E., Horton, E. B., Folland, C. K., Alexander, L. V., Rowell, D. P., Kent, E. C., and Kaplan, A.: Global analyses of sea surface temperature, sea ice, and night marine air temperature since the late nineteenth century, J. Geophys. Res., 108, 4407, doi:10.1029/2002JD002670, 2003.

Rignot, E., Velicogna, I., van der Broeke, M. R., Monaghan, A., and Lenaerts, J.: Acceleration of the contribution of the Greenland and Antarctic ice sheets to sea level rise. Geophys. Res. Lett., 38, L05503, doi:10.1029/2011GL046583, 2011.

Silva, T. A. M., Bigg, G. R., and Nicholls, K. W.: The contribution of giant icebergs to the Southern Ocean freshwater flux, J. Geophys. Res., 111, C03004, doi:10.1029/2004JC002843, 2006.

Stephenson, G. R., Sprintall, J., Gille, S. T., Vernet, M., Helly, J. J., Kaufmann, R. S.: Subsurface melting of a free-floating Antarctic iceberg, Deep-Sea Res. Pt. II, 58, 1336-1345, doi:10.1016/j.dsr2.2010.11.009, 2011.

Tournadre, J., Girard-Ardhuin, F., and Legrésy, B.: Antarctic icebergs distributions, 2002-2010, J. Geophys. Res., 117, C05004, doi:10.1029/2011JC007441, 2012.

van den Berk, J. and Drijfhout, S. S.: A realistic freshwater forcing protocol for ocean-coupled climate models, Ocean Model., 81, 36-48, doi:10.1016/j.ocemod.2014.07.003, 2014.

Wadley, M. R. and Bigg, G. R.: Implementation of variable time stepping in an ocean general circulation model, Ocean Model., $1,71-80,2000$. 
Watkins, S. J., Maher, B. A., and Bigg, G. R.: Ocean circulation at the Last Glacial Maximum: a combined modelling and magnetic proxy-based study, Paleoceanogr., 22, PA2204, doi:10.1029/2006PA001281, 2007.
Worby, A. P., Geiger, C. A., Paget, M. J., van Woert, M. L., Ackley, S. F., and DeLiberty, T. L.: Thickness distribution of Antarctic sea ice, J. Geophys. Res., 113, C05S92, doi:10.1029/2007JC004254, 2008. 